\title{
ANALISIS PERBANDINGAN PEMASARAN KENDARAAN RODA TIGA GAJAH 150 CC DAN GAJAH 200 CC
}

\author{
Juwanti, Venny Adhita Octaviani \\ Fakultas Ilmu Sosial dan Ilmu Politik Universitas Kapuas Sintang \\ Jln. Y.C.Oevang Oeray No.92 Sintang, Kalimantan Barat \\ Email: adhitavenny@gmail.com
}

\begin{abstract}
Abstrak: Penelitian ini bertujuan untuk mengetahui dan menganalisis perbandingan pemasaran Kendaraan Roda Tiga Gajah 150cc dan Gajah 200cc di Dealer APPKTM Sintang Asean Motor Tahun 2018. Jumlah sampel yang digunakan yaitu sebanyak 42 responden dengan teknik pengambilan sampel dengan menggunakan sampel jenuh yang artinya seluruh populasi dalam penelitian ini dijadikan sampel. Metode analisis yang digunakan pada penelitian ini adalah analisis uji beda dengan bantuan program SPSS. Berdasarkan hasil pengolahan data yang telah dilakukan, diperoleh hasil penelitian yakni tidak terdapat perbedaan pemasaran antara kendaraan roda tiga Gajah 150cc dengan Gajah 200cc pada Dealer APPKTM Sintang Asean Motor, yang ditunjukan dengan besarnya tingkat signifikansi independent sample $\mathrm{t}$ test sebesar 0,861 yang lebih besar dari 0,05, sehingga Ha ditolak dan $\mathrm{H} 0$ diterima. Adapun kesimpulan dari penelitian ini yakni tidak terdapat perbedaan pemasaran kendaraan roda tiga Gajah 150cc dengan Gajah 200cc pada Dealer APPKTM Sintang Asean Motor. Terdapat beberapa hal yang peneliti sarankan dalam penelitian ini antara lain mengharapkan agar perusahaan senantiasa memberikan pelayanan terbaik dan meningkatkan strategi pemasaran yakni produk, harga, tempat dan promosi untuk kendaraan roda tiga Gajah 150cc dan Gajah 200cc agar volume penjualan dari kedua produk tersebut dapat meningkat dan dapat memberikan keuntungan bagi perusahaan.
\end{abstract}

Kata Kunci : Perbandingan Pemasaran

Peningkatan penjualan merupakan target yang harus dicapai perusahaan. Peningkatan penjualan yang dilakukan perusahaan merupakan faktor penentu berhasil tidaknya perusahaan. Jika perusahaan melakukan penjualan dibawah target yang direncanakan, maka perusahaan tersebut dapat dikatakan gagal dalam pemasaran produknya. Sebaliknya jika perusahaan mampu menjual melewati target yang direncanakan, maka perusahaan tersebut berhasil dalam usaha pemasaran produknya dan perusahaan akan memperoleh keuntungan yang maksimal. Untuk memperoleh keuntungan yang maksimal, perusahaan harus dapat meningkatkan penjualan produknya. Oleh karena itu, perusahaan harus selalu menentukan strategi pemasaran yang tepat, agar penjualan produknya meningkat.

PT. Asean Motor Internasional (AMI) merupakan salah satu dealer nasional sepeda motor yang ditunjuk oleh PT Asia Putra Perkasa sebagai main dealer nasional sepeda motor merek APPKTM (singkatan dari Asia Putra Perkasa Kingtown Tian Ma). Dealer ini menyediakan icon transportasi motor roda tiga yang dikenal dengan merek APPKTM Gajah.
Dewasa ini kendaraan roda tiga begitu banyak diminati oleh konsumen, terutama konsumen yang memiliki usaha pertokoan, logistik, perkebunan, peternakan dan lain sebagainya karena dianggap lebih efisien. Keuntungan yang didapat oleh konsumen jika menggunakan APPKTM Gajah diantara adalah : Harga kendaraan terjangkau, Perawatan mudah dan murah sesuai dengan kendaraan roda dua, Pajak kendaraan sesuai dengan kendaraan roda dua, SIM sesuai dengan kendaraan roda dua, Hemat BBM, Bengkel resmi tersedia, Sparepart murah sesuai dengan kendaraan roda dua, Penggunaan seperti mengendarai kendaraan roda dua, dan lain sebagainya.

Dengan keunggulan tersebut, PT Asean Motor selalu berusaha memberikan pelayanan terbaik agar dapat menarik minat konsumen untuk membeli APPKTM Gajah. APPKTM Gajah memiliki beberapa type yang dirancang khusus untuk konsumen pengguna kendaraan roda tiga. Type APPKTM Gajah tersebut antara lain Gajah SX 150cc, Gajah 150cc Radiator, Gajah 200cc Radiator dan Gajah 500cc Diesel. Berikut daftar harga APPKTM Gajah yang dipasarkan di Dealer Asean Motor Cabang Sintang : 
Tabel 1. Daftar Harga Kendaraan Roda Tiga APPKTM Gajah Tahun 2018

\begin{tabular}{|c|c|c|}
\hline Type & Ukuran Bak & Harga \\
\hline \multirow{2}{*}{ Gajah SX 150cc } & Bak $1,5 \mathrm{~m}$ & Rp. 28.000.000,- \\
\hline & Baktor $1,5 \mathrm{~m}$ & Rp. 32.500.000,- \\
\hline \multirow[t]{3}{*}{ Gajah 150cc Radiator } & Bak $1,5 \mathrm{~m}$ & Rp. 29.950.000,- \\
\hline & Bak $1,8 \mathrm{~m}$ & Rp. 30.950.000,- \\
\hline & Bak 1,8 m + DP & Rp. 31.950.000,- \\
\hline \multirow[t]{3}{*}{ Gajah 200cc Radiator } & Bak $1,8 \mathrm{~m}$ & Rp. 32.500.000,- \\
\hline & Bak 1,8 + DP & Rp. 33.500.000,- \\
\hline & Bak 2 m + DP & Rp. 34.250.000,-- \\
\hline \multirow[t]{3}{*}{ Gajah 500cc Diesel } & Bak $2 \mathrm{~m}$ & Rp. 39.750.000,- \\
\hline & Bak 2,3 m & Rp. 40.750.000,- \\
\hline & Bak 2,6 m & Rp. 41.750.000,- \\
\hline
\end{tabular}

Sumber: PT ASEAN Motor, Tahun 2019.

Kendaraan roda tiga APPKTM Gajah 150 cc dan Gajah 200 c merupakan kendaraan roda tiga yang paling banyak dicari oleh konsumen. Berikut data penjualan kendaraan roda tiga Gajah $150 \mathrm{cc}$ dan Gajah $200 \mathrm{cc}$ di dealer APPKTM Sintang Asean Motor :

Tabel 2. Data Penjualan Kendaraan Roda Tiga Gajah 150 cc dan Gajah 200 cc di Dealer APPKTM Sintang Asean Motor Tahun 2016-2018

\begin{tabular}{|c|l|l|l}
\hline Jenis Kendaraan & Tahun 2016 & Tahun 2017 & Tahun 2018 \\
\hline Gajah 150 cc & Rp. 54.900.000,- & Rp. 116.150.000,- & Rp. 118.000.000,- \\
\hline Gajah 200 cc & Rp. 154.700.000,- & Rp. 348.050.000.- & Rp. 263.250.000,- \\
\hline Jumlah & Rp. 209.600.000,- & Rp. 464.200.000,- & Rp. 381.250.000,- \\
\hline
\end{tabular}

Sumber: Data Dealer APPKTM Sintang Asean Motor, Diolah Tahun 2019.

Berdasarkan tabel diatas terlihat bahwa penjualan kendaraan roda tiga Gajah $150 \mathrm{cc}$ dari tahun 2016 sampai dengan tahun 2018 mengalami peningkatan, sejalan dengan kendaraan Roda Tiga Gajah $200 \mathrm{cc}$ juga mengalami peningatan. Namun selisih penjualan kedua jenis kendaraan tersebut terlihat sangat jauh. Oleh karena itu penulis tertarik untuk meneliti perbandingan pemasaran Kendaran Roda Tiga Gajah 150 cc dengan Gajah 200 cc pada Dealer APPKTM Sintang Asean Motor.

\section{Rumusan Masalah}

Adapun permasalahan dalam penelitian ini adalah "bagaimanakah perbandingan pemasaran kendaraan roda tiga Gajah 150 cc dan Gajah 200 cc di dealer APPKTM Sintang Asean Motor tahun 2018?".

\section{Tujuan Penelitian}

Adapun tujuan penelitian dalam penelitian ini adalah untuk mengaetahui dan menganalisis perbandingan pemasaran kendaraan roda tiga Gajah 150 cc dan Gajah $200 \mathrm{cc}$ di dealer APPKTM Sintang Asean Motor tahun 2018.

\section{Landasan Teori}

Pemasaran merupakan suatu kegiatan pokok yang dilakukan oleh pengusaha dalam rangka menjual produknya. Pemasaran berbeda dengan

penjualan. Penjualan merupakan bagian dari pemasaran. Ketika sebuah perusahaan ingin melakukan kegiatan pemasaran, perusahaan tersebut harus mampu membaca dan mengetahui apa yang menjadi kebutuhan dan keinginan dari konsumen.

Pada umumnya para pengusaha mempunyai tujuan mendapatkan laba tertentu (mungkin maksimal), dan mempertahankan atau bahkan berusaha meningkatkannya untuk jangka waktu lama. Tujuan tersebut dapat direalisir apabila kegiatan pemasaran dapat dilaksanakan seperti yang direncanakan. Dengan demikian tidak berarti bahwa barang atau jasa yang terjual selalu akan menghasilkan laba.

Volume penjualan merupakan hasil akhir yang dicapai perusahaan dari hasil penjualan produk yang dihasilkan oleh perusahaan tersebut. Volume penjualan tidak memisahkan secara tunai maupun kredit tetapi dihitung secara keseluruhan dari total yang dicapai. Seandainya volume penjualan meningkat dan biaya distribusi menurun maka tingkat pencapaian laba perusahaan meningkat tetapi sebaliknya bila volume penjualan menurun maka pencapaian laba perusahaan juga menurun.

Untuk meningkatkan volume penjualan, perusahaan harus dapat menentukan strategi yang pas untuk pemasaran produk tersebut. Menurut Kotler (2000 :12), strategi pemasaran suatu produk 
dikenal dengan 4P yakni product, price, place dan promotion.

Produk menurut Kotler (2002:59) "adalah segala sesuatu yang dapat ditawarkan ke suatu pasar untuk memenuhi kebutuhan”. Selanjutnya menurut Kotler (2002:59) suatu produk harus memiliki atribut sebagai berikut : 1) kualitas produk, 2) fitur produk, dan 3) desain produk.

Price atau harga menurut Swastha (2002 :105) adalah jumlah uang yang dibutuhkan untuk mendapatkan sejumlah produk atau jasa. Hal-hal yang perlu diperhatikan dalam menetapkan harga yakni biaya, keuntungan praktik saingan dan perubahan keinginan pasar. Besarnya jumlah uang yang dikeluarkan untuk mendapatkan atau memiliki suatu barang ditentukan oleh kesepakatan antara pembeli dan penjual itu sendiri.

Selanjutnya adalah strategi place atau saluran distribusi yakni pendistribusian barang dan jasa dari produsen sampai ke konsumen. Menurut Swastha (2002: 106), saluran distribusi pemasaran memegang peranan dalam membantu menyampaikan barang atau jasa dari pihak produsen ke konsumen. Dalam hal ini ada tiga jenis interaksi yang mempengaruhi distribusi yaitu: 1) Konsumen mendatangi pemberi jasa (perusahaan). 2) Pemberi jasa mendatangi konsumen dan 3) Pemberi jasa dan konsumen tidak bertemu secara langsung.

Selanjutnya strategi promotion atau promosi. Promosi menurut Gitosudarmo (2000:237) "adalah merupakan kegiatan yang ditujukan untuk mempengaruhi konsumen agar mereka dapat menjadi kenal akan produk yang ditawarkan oleh perusahaan kepada mereka dan kemudian mereka menjadi senang lalu membeli produk tersebut". Terdapat lima sarana promosi utama menurut Kotler dan Amstrong, (2008:117) yakni sebagai berikut: 1)Periklanan (advertising), 2) Promosi penjualan (sales promotion), 3) Hubungan masyarakat (public relation), 4) Penjualan personal (personal sellin), dan 5) Pemasaran langsung (direct marketing).

Keempat strategi tersebut (product, price, place dan promotion) biasanya digunakan oleh perusahaan untuk memasarkan produk mereka. Namun tidak semua strategi dapat membantu perusahaan dalam meningatkan volume penjualan. Oleh karena itu perusahaan harus melakukan eksperimen melalui perbandingan penjualan.

Perbandingan pemasaran suatu produk bertujuan untuk melihat seberapa besar tingkat perbedaan tersebut, dan strategi apa yang dapat di terapkan oleh perusahaan agar penjualannya semakin meningkat.

\section{Hipotesis}

Adapun hipotesis dalam penelitian ini adalah sebagai berikut:

1. Ho = tidak terdapat perbedaan pemasaran kendaraan roda tiga Gajah $150 \mathrm{cc}$ dan Gajah 200 cc di Dealer APPKTM Sintang.

2. $\mathrm{Ha}=$ terdapat perbedaan pemasaran kendaraan roda tiga Gajah $150 \mathrm{cc}$ dan Gajah $200 \mathrm{cc}$ di Dealer APPKTM Sintang.

\section{Metode Penelitian}

Rancangan penelitian dalam penelitian ini berdasarkan pendekatannya adalah penelitian kuantitatif dengan berbentuk penelitian komparatif. Menurut Ulber (2005) penelitian komparatif adalah penelitian yang membandingkan dua gejala atau lebih. Penelitian komparatif dapat berupa komparatif deskriptif (descriptive comparative) maupun komparatif korelasional (correlation comparative).

Komparatif deskriptif membandingkan variabel yang sama untuk sampel yang berbeda. Selanjutnya menurut Hasan (2002: 126-127) analisis komparasi atau perbandingan adalah prosedur statistik guna menguji perbedaan diantara dua kelompok data (variabel) atau lebih. Uji ini bergantung pada jenis data (nominal, ordinal, interval/rasio) dan kelompok sampel yang diuji. Dalam penelitian ini peneliti ingin membandingkan penjualan kendaraan roda tiga Gajah $150 \mathrm{cc}$ dengan kendaraan roda tiga Gajah 200cc di Dealer APPKTM Sintang Asean Motor dengan melakukan studi komparasi.

Populasi dalam penelitian ini adalah seluruh konsumen yang pernah membeli kendaraan roda tiga Gajah di Dealer APPKTM Sintang Asean Motor Tahun 2016-2018 yang berjumlah 42 konsumen.

Teknik pengambilan sampel yang akan digunakan oleh peneliti dalam penelitian ini adalah sampel jenuh. Dikarenakan jumlah populasinya tidak lebih besar dari 100 orang responden, maka penulis mengambil $100 \%$ jumlah populasi yang ada. Sehingga sampel pada penelitian ini yakni seluruh konsumen yang telah membeli kendaraan roda tiga Gajah pada Dealer APPKTM Sintang Asean Motor yang berjumlah 42 responden.

Analisis data pada penelitian dilakukan dengan menggunakan uji statistik yang disebut Uji Beda. Menurut Misbahuddin (2013), Uji beda adalah bentuk analisis variabel (data) untuk mengetahui perbedaan diantara dua kelompok data (variabel) atau lebih. 
Hasil Penelitian dan Pembahasan

Hasil Uji Validitas Dan Reliabilitas

Hasil uji validitas data penelitian dapat dilihat pada tabel sebagai berikut :

Tabel 3. Hasil Pengujian Validitas

\begin{tabular}{|c|c|c|c}
\hline No.Item & Nilai r Hitung & Nilai r Syarat & Hasil Uji \\
\hline & & & \\
\hline Pertanyaan 1 & 0,692 & 0,30 & Valid \\
\hline Pertanyaan 2 & 0,769 & 0,30 & Valid \\
\hline Pertanyaan 3 & 0,689 & 0,30 & Valid \\
\hline Pertanyaan 4 & 0,708 & 0,30 & Valid \\
\hline Pertanyaan 5 & 0,694 & 0,30 & Valid \\
\hline Pertanyaan 6 & 0,718 & 0,30 & Valid \\
\hline Pertanyaan 7 & 0,544 & 0,30 & Valid \\
\hline Pertanyaan 8 & 0,732 & 0,30 & Valid \\
\hline Pertanyaan 9 & 0,635 & 0,30 & Valid \\
\hline Pertanyaan 10 & 0,461 & 0,30 & Valid \\
\hline
\end{tabular}

Sumber: Data primer, diolah tahun 2019.

Tabel 3 tersebut diatas menunjukan nilai $r$ hitung masing-masing item pertanyaan/pernyataan pada variabel penelitian lebih besar dari $\mathrm{r}$ yang dipersyaratkan. Sehingga dapat disimpulkan bahwa seluruh item pertanyaan dalam instrumen penelitian

ini dapat dinyatakan valid dan layak jika digunakan untuk mengukur perbandingan pemasaran Kendaran Roda Tiga Gajah 150 cc dengan Gajah 200 cc pada Dealer APPKTM Sintang Asean Motor.

Adapun hasil olahan data mengenai uji reliabilitas data instrumen penelitian dapat dirangkum pada tabel 4 sebagai berikut:

Tabel 4. Hasil Uji Reliabilitas

Reliability Statistics

\begin{tabular}{|c|c|}
\hline Cronbach's Alpha & N of Items \\
\hline 0,903 & 10 \\
\hline
\end{tabular}

Sumber: Data Primer, Diolah, 2019

Berdasarkan hasil pengujian reliabilitas yang terdapat pada tabel 4 tersebut, maka dapat disimpulkan bahwa seluruh item dalam instrumen penelitian dinyatakan reliabel dan konsisten jika digunakan untuk mengukur perbandingan pemasaran Kendaran Roda Tiga Gajah $150 \mathrm{cc}$ dengan Gajah 200 cc pada Dealer APPKTM Sintang Asean Motor.

\section{Uji Beda (Independent Sample T Test)}

Independent Sample $t$ test digunakan untuk mengetahui ada atau tidaknya perbedaan rata-rata antara dua kelompok sampel yang tidak berhubungan. Jika ada perbedaan, rata-rata manakah yang lebih tinggi. Data yang digunakan biasanya berskala interval atau rasio. Adapun hasil dari independent sample $t$ test dalam penelitian ini yakni dapat dilihat pada tabel berikut:Berdasarkan 
Independent Samples Test

\begin{tabular}{|c|c|c|c|c|c|c|c|c|c|c|}
\hline & \multicolumn{2}{|c|}{$\begin{array}{c}\text { Levene's } \\
\text { Test for } \\
\text { Equality of } \\
\text { Variances } \\
\end{array}$} & \multicolumn{7}{|c|}{ t-test for Equality of Means } \\
\hline & & \multirow[b]{2}{*}{$\mathrm{F}$} & \multirow[b]{2}{*}{ Sig. } & \multirow[b]{2}{*}{$\mathrm{t}$} & \multirow[b]{2}{*}{ df } & \multirow{2}{*}{$\begin{array}{l}\text { Sig. } \\
\text { (2- } \\
\text { tailed) }\end{array}$} & \multirow{2}{*}{$\begin{array}{c}\text { Mean } \\
\text { Differenc } \\
\mathrm{e} \\
\end{array}$} & \multirow{2}{*}{$\begin{array}{l}\text { Std. Error } \\
\text { Difference }\end{array}$} & \multicolumn{2}{|c|}{$\begin{array}{l}95 \% \text { Confidence } \\
\text { Interval of the } \\
\text { Difference }\end{array}$} \\
\hline & & & & & & & & & Lower & Upper \\
\hline $\mathrm{X}$ & $\begin{array}{l}\text { Equal } \\
\text { variances } \\
\text { assumed } \\
\text { Equal } \\
\text { variances } \\
\text { not assumed }\end{array}$ & .006 & .938 & $\begin{array}{l}.176 \\
.187\end{array}$ & 37.657 & $\begin{array}{l}.861 \\
.853\end{array}$ & .423 & 2.264 & $\begin{array}{l}-4.436 \\
-4.162\end{array}$ & 5.282 \\
\hline
\end{tabular}

Sumber: Data Primer, Diolah 2019.

output di atas diketahui nilai Sig. Levenes Test for Equality of Variances adalah sebesar 0,938>0,05 maka dapat diartikan bahwa varians data antara kelompok kendaraan roda tiga $150 \mathrm{cc}$ dengan kendaraan roda tiga 200cc adalah homogen atau sama (Sujarweni, 2014:99). Sehingga penafsiran tabel output independent sample test di atas berpedoman pada nilai yang terdapat pada dalam tabel "equal variance assumed".

Berdasarkan tabel output "independent sample test" pada bagian "Equal variances assumed" diketahui nilai Sig. (2-tailed) sebesar $0,861>0,05$, sehingga sebagaimana dasar pengambilan keputusan dalam uji independent sample t test dapat disimpulkan bahwa $\mathrm{H} 0$ diterima dan Ha ditolak. Dengan demikian dapat disimpulkan bahwa tidak terdapat perbedaan pemasaran kendaraan roda tiga Gajah $150 \mathrm{cc}$ dan Gajah 200 cc di Dealer APPKTM Sintang.

\section{Pembahasan}

Berdasarkan output uji beda atau independent sample t test, diperoleh hasil bahwa nilai signifikansi t hitung > dari 0,05 . Ini menunjukkan bahwa hipotesis yang diterima di dalam penelitian ini adalah $\mathrm{H} 0$, yaitu tidak terdapat perbedaan pemasaran kendaraan roda tiga Gajah 150 cc dan Gajah 200 cc di Dealer APPKTM Sintang.

Dealer APPKTM Sintang Asean Motor menuturkan tidak pernah membedakan dalam memasarkan produk-produknya. Strategi yang digunakan terhadap kedua produk tersebut juga dapat dikatakan sama. Baik dari sisi pengemasan produk, penentuan harga, saluran distribusi dan promosi produk tersebut.

Dari sisi pengemasan, baik kendaraan roda tiga jenis Gajah 150cc dan Gajah 200cc hanya dibedakan dengan luas bak belakang. Dimana untuk Gajah 150cc memiliki bak yang lebih kecil dari Gajah 200cc. Dan dalam penentuan harga disesuaikan dengan masing-masing produk dan besarnya bak. Untuk harga kendaraan roda tiga Gajah 150cc yang memiliki bak 1,5 m ditetapkan harga sebesar Rp.29.950.000,00, untuk Gajah $150 \mathrm{cc}$ yang memiliki ukuran bak $1,8 \mathrm{~m}$ ditetapkan harga sebesar Rp. 30.950.000,00, sedangkan Gajah $200 \mathrm{cc}$ memiliki ukuran bak sebesar $1,8 \mathrm{~m}$ yang harganya ditetapkan sebesar Rp. 32.500.000,00 dan Gajah 200cc yang memiliki ukuran bak sebesar $2 \mathrm{~m}$ ditetapkan harga sebesar Rp. 34.250.000,00. Harga tersebut adalah harga yang berlaku pada setiap dealer APPKTM yang ada di Kalimantan Barat. Bagi sebagian masyarakat selisih harga dari Gajah $150 \mathrm{cc}$ dan 200cc tidak terlalu signifikan, sehingga mereka lebih memilih Gajah 200cc yang memiliki kapasitas bak yang lebih besar dengan harga yang lebih sedikit mahal dari Gajah 150cc.

Dari sisi saluran distribusi, saat ini saluran distribusi untuk kendaraan Roda Tiga Gajah baik $150 \mathrm{cc}$ maupun 200cc masih dipasarkan pada daerah Kabupaten. Penempatan produk-produk tersebut juga masih melihat kondisi pasar yang paling banyak membutuhkan dan ramai penduduk. Dan untuk mempermudah pemasaran kedua produk tersebut Dealer APPKTM Sintang Asean Motor telah melakukan beberapa upaya promosi yang sayangnya masih sangat terbatas. Promosi yang dilakukan antara lain dengan menginformasikan produk tersebut melalui media radio lokal, pembagian brosur dan pemasaran melalui media sosial dengan menggunakan internet. Strategi pemasaran adalah cara yang dapat dilakukan oleh pemasar dalam rangka untuk memasarkan dan menjual produknya. Semakin baik strategi pemasaran yang diterapkan akan berdampak pada meningkatnya barang yang akan terjual. Hal ini sejalan dengan penelitian yang dilakukan oleh Sinulingga (2015), Nurafni dkk (2017) dan Taroreh dkk (2018) yang menyatakan 
bahwa strategi pemasaran berpengaruh terhadap penjualan produk.

\section{Kesimpulan dan Saran}

Nilai signifikansi pada Levene's Test for Equality of Variance menunjukkan nilai 0,938 > dari 0,05 yang berarti bahwa varians data antara kelompok kendaraan roda tiga Gajah 150cc dan Gajah 200cc adalah homogen atau sama. Hasil uji beda melalui idenpendent sample $t$ test menunjukkan bahwa nilai signifikansi dua arah (Sig 2-Tailed) adalah sebesar 0,861> dari 0,05, sehingga dapat disimpulkan bahwa tidak terdapat perbedaan pemasaran kendaraan roda tiga Gajah 150cc dan Gajah 200cc pada Dealer APPKTM Sintang Asean Motor. Terdapat beberapa hal yang dapat disarankan antara lain sebagai berikut: 1) Diharapkan agar perusahaan senantiasa memberikan dan meningkatkan pelayanan terbaik agar dapat memuaskan konsumen. 2) Diharapkan agar perusahaan lebih kreatif dan inovatif dalam menetapkan strategi pemasaran baik dari sisi produk, harga, tempat dan promosi yang diberikan untuk kendaraan roda tiga Gajah $150 \mathrm{cc}$ dan Gajah 200cc pada Dealer APPKTM Sintang Asean Motor, dan 3) Diharapkan agar perusahan senantiasa meningkatkan promosi dari kendaraan roda tiga khususnya Gajah $150 \mathrm{cc}$.

\section{Daftar Pustaka}

Gitosudarmo, Indriyo. 2000. Manajemen Pemasaran, Cetakan Keenam. Yogyakarta :Penerbit BPFE.

Hasan, M. Iqbal. 2002. Pokok-pokok Materi Metodologi Penelitian dan Aplikasinya. Bogor: Ghalia Indonesia.

Kotler, Philip. 2000. Manajemen Pemasaran : Analisis, Perencanaan, Implementasi, dan Kontrol. Jakarta: PT. Prehallindo. 2002. Manajemen Pemasaran Edisi Milenium Jilid 2. Jakarta: PT. Prenhallindo.
Kotler, Philip dan Armstrong, G 2008, PrinsipPrinsip Pemasaran. Jakarta: Erlangga.

Misbahudin, Iqbal Hasan. 2013. Analisis Data Penelitian Dengan Statistik. Jakarta: Bumi Aksara.

Nurafni dkk. 2017. Strategi Pemasaran Mobil Merek Daihatsu pada Dealer Daihatsu Jember. Jurnal Ilmiah Ilmu Pendidikan, Ilmu Ekonomi dan Ilmu Sosial, Volume 11 Nomor 2 ISSN: $1907-$ 9990

Sinulingga. 2015. Pengaruh Strategi Pemasaran terhadap volume penjualan pada PT. Citra Mandiri Lestari Medan. Jurnal Mantik Penusa, Volume 17 Nomor 1 ISSN: 2088-3943.

Swastha, Basu dan Ibnu Sukotjo. 2002. Pengantar Bisnis Modern. Edisi Keenam. Yogyakarta: Liberty.

Taroreh, Gheany Andrea dkk. 2018. Marketing Strategy Analysis in Increasing the Sales Volume of Mitsubishi Xpander Cars at PT Bosowa Berlian Motor Kairagi. Jurnal Emba Volume 6 Nomor 4, ISSN: 2303-1174.

Ulber, Silalahi 2005. Metode Penelitian Sosial. Bandung : Unpar Press. 